\title{
MOMORDICA CHARANTIA NANO DRY POWDER ORAL FORMULATION IN CONTROLLING HISTAMINE-INDUCED BRONCHOSPASM
}

\author{
KARTHIKA P, BHUVANESWARI K*, BALACHANDER R
}

Department of Pharmacology, PSG Institute of Medical Sciences and Research, Coimbatore, Tamil Nadu, India. Email: nandabhuvana@gmail.com Received: 18 February 2019, Revised and Accepted: 19 June 2019

\begin{abstract}
Objective: Momordica charantia (MC) (bitter gourd) is known traditionally to possess medicinal values. This edible vegetable is known for its antiinflammatory properties and has been studied for its bronchospasm preventive action. With the recent development in nanoformulations, this study was done to identify the effectiveness of MC nanoformulation in comparison to crude MC formulation in protecting animal from histamine-induced bronchospasm.
\end{abstract}

Methods: The optimized MC nanoformulation was prepared with polyethylene glycol and soy phosphatidylcholine. The MC crude powder was prepared by drying in hot air oven and grinding in a blender. Eight guinea pigs of both sexes were given once daily MC nanoformulation per oral by mixing with water for 7 days. Evaluation of the formulation was done on the $2^{\text {nd }}$, $4^{\text {th }}$, and $6^{\text {th }}$ h on day 1 and day 7 after administration of MC for protection in developing pre-convulsive dyspnea due to histamine-induced bronchospasm.

Results: An analysis of variance test revealed statistically significant results in the protection of animals from developing bronchospasm after treatment with the MC nanoformulation in comparison to the control values. About $75 \%$ of animals were protected from developing bronchospasm on day 7 attributing to the cumulative effect of nanoformulation.

Conclusion: The study proved that the MC nanoformulation could effectively prevent histamine-induced bronchospasm in guinea pigs.

Keywords: Momordica charantia, Nanoformulation, Anti-inflammatory.

(C) 2019 The Authors. Published by Innovare Academic Sciences Pvt Ltd. This is an open access article under the CC BY license (http://creativecommons. org/licenses/by/4. 0/) DOI: http://dx.doi.org/10.22159/ajpcr.2019.v12i8.32655

\section{INTRODUCTION}

Momordica charantia (MC) also known as bitter gourd is a common edible vegetable, known to possess medicinal values [1]. It is traditionally known for its medicinal properties such as anti-diabetic, anticancer, anti-inflammation, antivirus, and for cholesterol-lowering effects. It contains many phenol compounds that may have the potential as antioxidant and anti-mutagen [2]. The fruit, stems, leaves, and roots of MC have all been used in traditional medicine to help treat ailments such as hyperlipidemia, digestive disorders, microbial infections, and menstrual problems [3]. Studies have also shown that bitter melon has anticarcinogenic properties and can be used as a cytotoxic agent [4]. Many studies had confirmed the electrolyte balancing property, antiinflammatory, and antioxidant property of MC with cytokine-inhibiting activity $[5,6]$. The anti-inflammatory activity of MC has been confirmed by its action through, interleukin 1 (IL)-1, IL-2, IL-6, IL-8, tumor necrosis factor- $\alpha$, and nuclear factor kappa $\beta$ normalization both in animal and human studies.

Asthma is a chronic inflammatory disorder of the airways and needs long-term use of anti-inflammatory drugs to control symptoms [7]. MC is known for its anti-inflammatory action and previous done have proven its property to prevent histamine-induced bronchospasm. However, no studies have been done on the nanoformulation of MC. This study was proposed as an attempt to prove the benefitting properties of MC nanoformulation pre-clinically in guinea pigs for its anti-inflammatory potent action in preventing histamine-induced bronchospasm.

The purpose of this study was to maximize the pharmacological property of the MC nanoformulation by making it available for maximum systemic absorption. As there is variation in the various extracts and powders of $\mathrm{MC}$, there is probably variation in the formulation we provide to the patients. One such recent advance is the nanocapsule formulation [8]. They are considered as weapons of new drug delivery system. Hence, this study was proposed to identify the effectiveness of MC nanoformulation in protecting guinea pigs from histamine-induced bronchospasm in whole animal model.

\section{METHODS}

The study was done in two parts. First, the nanoformulation of MC and crude dry powder formulation of MC were prepared and shelf life of the two compounds was tested for 180 days. The second part of the study dealt with administration of the nanoformulation of MC per oral in guinea pigs and its efficacy in preventing histamine-induced bronchospasm was evaluated.

\section{Preparation of nanoformulation of MC}

MC crude powder was prepared by drying in hot air oven and grinding in a blender. Nanosuspension of crude bitter gourd powder was prepared by probe sonication and lyophilization technique $[9,10]$. Briefly, sufficient quantity (10 g) of crude bitter gourd powder was weighed and added to the aqueous phase (water) containing surfactant soy phosphatidylcholine. The aqueous mixture was sonicated using a bath sonicator for $15 \mathrm{~min}$ to get a homogeneous mixture. The resulting homogeneous mixture was sonicated using an ultrasonic probe sonicator (Vibra Sonics) for $30 \mathrm{~min}$ at $20,000 \mathrm{~Hz}$ to produce bitter gourd nanosuspension. This sample of nanosuspension particle size was measured using Malvern Zetasizer (Nano ZS90, Malvern Instruments) at $25^{\circ} \mathrm{C}$ and measured 291.3 diameter nanometer (d. $\mathrm{nm}$ ). To improve the bioavailability of this MC nanoproduct, we added polyethylene glycol (PEG) and deep freezing was done at $-80^{\circ} \mathrm{C}$ for $4 \mathrm{~h}$ following this, the sample was again freeze-dried in a lyophilizer (Lyodel) at a temperature and pressure of $-50^{\circ}$ and -1 bars, respectively, for $48 \mathrm{~h}$ to form powder. 
The dry nanoparticles were, hence, ready and the final particle size noted was $536.4 \mathrm{~d}$. nm [11].

Following this, a 180 days stability test was done on both the formulations of MC, filled in gelatin capsules and found that both were stable in room temperature $\left(25^{\circ}\right)$ and high temperature $\left(45^{\circ}\right)$. Stability was tested for its color, shape, consistency, $\mathrm{pH}$, weight, and disintegration in acid buffers.

Protection of histamine-induced bronchospasm by MC nanopowder (Fig. 1)

Eight adult guinea pigs of both sexes were chosen and the animals were kept in rooms under standard conditions. The animals were provided with ambient temperature of $25^{\circ} \mathrm{C}$ and $55 \%$ relative humidity, $12 \mathrm{~h}$ light period. Granular mixed feed and drinking water were available for all animals ad libitum throughout the experiment. The Institutional Animal Ethics Committee approved the study and the study was conducted strictly with guidelines of ICMR and CPCSEA.

On day 1 , all the eight guinea pigs were weighed and animal dose of MC nanoformulation at $600 \mathrm{mg} / \mathrm{kg}$ and was administered orally after dissolving in drinking water. After $2 \mathrm{~h}$, the animals were exposed to $2 \%$ histamine aerosol for $120 \mathrm{~s}$ using histamine chamber. Preconvulsive dyspnea (PCD) was noted in seconds $[12,13]$. The same experiment was repeated after $4 \mathrm{~h}$ from the time of $\mathrm{MC}$ nanoformulation administration and the PCD values were noted in seconds.

Following this, all the eight guinea pigs were given MC nanoformulation at $600 \mathrm{mg} / \mathrm{kg} /$ day (standardized animal dose) OD from day 2 to day 7. On day 7 , the animals were again exposed to bronchospasm induction with $2 \%$ histamine aerosol chamber for $120 \mathrm{~s}$ from $2 \mathrm{~h}$ of MC nanoformulation administration. Bronchospasm protection activity for both the formulations of MC was observed. All the three sets of values to develop PCD (control value, day 1 value, and day 7 value) were tabulated for statistical analysis. The mean value for developing PCD in a control animal (before giving drug) was found to be $61.10 \mathrm{~s} \mathrm{[14].}$

\section{RESULTS}

The animals were administered with MC nanoformulation from day 1 to day 7 every day at $8 \mathrm{am}$. Protection for bronchospasm was observed on day 1 and day 7. The time to develop PCD was as follows:

Table 1: Particle size, polydispersion unit, and zeta potential of the formulation of MC

\begin{tabular}{llll}
\hline Formulations & $\begin{array}{l}\text { Particle } \\
\text { size }\end{array}$ & $\begin{array}{l}\text { PDI } \\
\text { (polydispersion index) }\end{array}$ & $\begin{array}{l}\text { Zeta } \\
\text { potential }\end{array}$ \\
\hline MC crude dry powder & $3953 \mathrm{~d}$. nm & 1.000 & -6.01 \\
MC nano dry & $534.6 \mathrm{~d} . \mathrm{nm}$ & 0.612 & -36.23 \\
powder (SPL+PEG) & & & \\
\hline
\end{tabular}

MC: Momordica charantia, PEG: Polyethylene glycol
On day 1, after $4 \mathrm{~h}$ from nanoformulation of $\mathrm{MC}$ administration, it was observed that 5 (62.5\%) animals were completely protected from PCD and three animals had prolonged duration in developing PCD compared with the previous exposure at $2 \mathrm{~h}$. (Further, exposure to histamine not done as $>50 \%$ of animals were protected at the end of $4 \mathrm{~h}$ ).

On day 7 , six animals (75\%) were completely protected from developing PCD, and hence, further, exposure to histamine was not done.

\section{Statistical analysis}

Analysis of variance (ANOVA) test was applied to compare the time difference to develop PCD in the animals in seconds between the three values (Day 1: $2 \mathrm{~h}$ and $4 \mathrm{~h}$ and day 7: $2 \mathrm{~h}$ ).

ANOVA test done between the three values has effectively demonstrated that all the animals were significantly protected from developing bronchospasm on day 1 after $4 \mathrm{~h}$ of MC nanodrug formulation ( $\mathrm{p}<0.01)^{*}$. Similarly, the animals were significantly protected from developing bronchospasm on day 7 after $2 \mathrm{~h}$ of drug administration $(\mathrm{p}<0.01)^{*}$.

Post-study animals were observed for a period of 2 months and no drug reactions or fatal effects were observed.

\section{DISCUSSION}

The aim of this study was to compare the efficacy and potency of MC nano dry formulation in contrast to its raw form as MC dry powder and MC fresh juice demonstrated by Bhuvaneswari et al. in animal model [14]. MC nanopowder was prepared and the particle size measurement showed $75 \%$ reduction in size of the particles in comparison to MC crude dry powder (Table 1). The nanoformulation was proved stable in high and low temperature after a 180 days stability testing (Table 2).

The mean of the control group was found to be $61.10 \mathrm{~s}$ [14]. Comparison was done for the same group animals on three different timings of histamine exposure post nanodrug administration and all the three sets of values were compared with ANOVA test (Table 3).

Guinea pigs being most sensitive for its histamine receptor sensitivity were chosen for this study [15]. Fig. 2 has clearly shown the number of animals protected from developing PCD. A normal control animal can hold from developing PCD for $61.1 \mathrm{~s}$ and animals treated with standard drug Montelukast could hold from developing PCD for 120 s, evinced from the previous studies [14].

Table 4 has illustrated that $50 \%$ of animals were able to attain protection from developing bronchospasm after $2 \mathrm{~h}$ of MC nano dry powder formulation administration. Following this, almost 100\% of animals showed prolongation of duration from developing PCD in comparison to the control, hence, proving the bronchospasm protective activity of MC nanodrug. On the same day, $62.5 \%$ of animals were completely protected from developing PCD after $4 \mathrm{~h}$ of MC nanodrug administration on day 1 and further exposure to histamine

Table 2: Physical properties of individual capsules from day 0 to day 180 at room temperature and high temperature

\begin{tabular}{lllll}
\hline Capsules & Color & Odor & Shape & Consistency \\
\hline MC crude dry powder & Yellow+red capsule color was not altered & No odor & Shape maintained & Dry capsules \\
MC nano dry powder (SPL+PEG) & Yellow+red capsule color was not altered & No odor & Shape maintained & Dry capsules \\
\hline
\end{tabular}

Table 3: ANOVA test between the time to develop PCD on day 1 at $2 \mathrm{~h}$ and $4 \mathrm{~h}$ and day 7 at $2 \mathrm{~h}$ with control value

\begin{tabular}{llllll}
\hline S. No. & Group & Mean & $\begin{array}{l}\text { Control } \\
\text { (mean value) }\end{array}$ & SD of group & $\begin{array}{l}\text { Post hoc ANOVA between group } \\
\text { and control }\end{array}$ \\
\hline 1. & Day 1 (2 h) & 69 & 61 & 20.1 & 0.496 \\
2. & Day 1 (4 h) & 113.5 & 61 & 9.5 & $0.000^{*}(\mathrm{p}<0.01)$ \\
3. & Day 7 (2 h) & 116.6 & 61 & 6.3 & $0.000^{*}(\mathrm{p}<0.01)$ \\
\hline
\end{tabular}

ANOVA: Analysis of variance, PCD: Preconvulsive dyspnea 
Table 4: Time to develop PCD on day 1 after $2 \mathrm{~h}$ and $4 \mathrm{~h}$ and day 7 after $2 \mathrm{~h}$ of MC nanoformulation administration

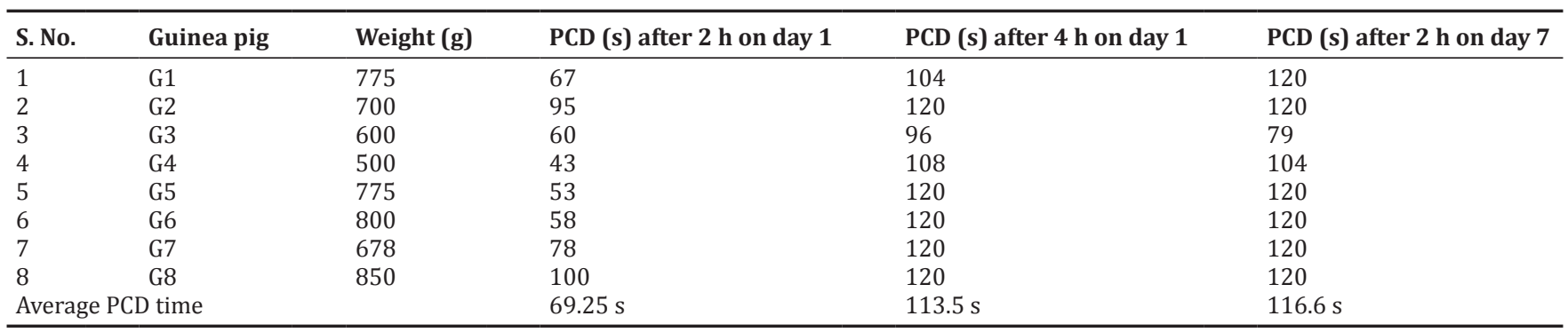

PCD: Preconvulsive dyspnea, MC: Momordica charantia

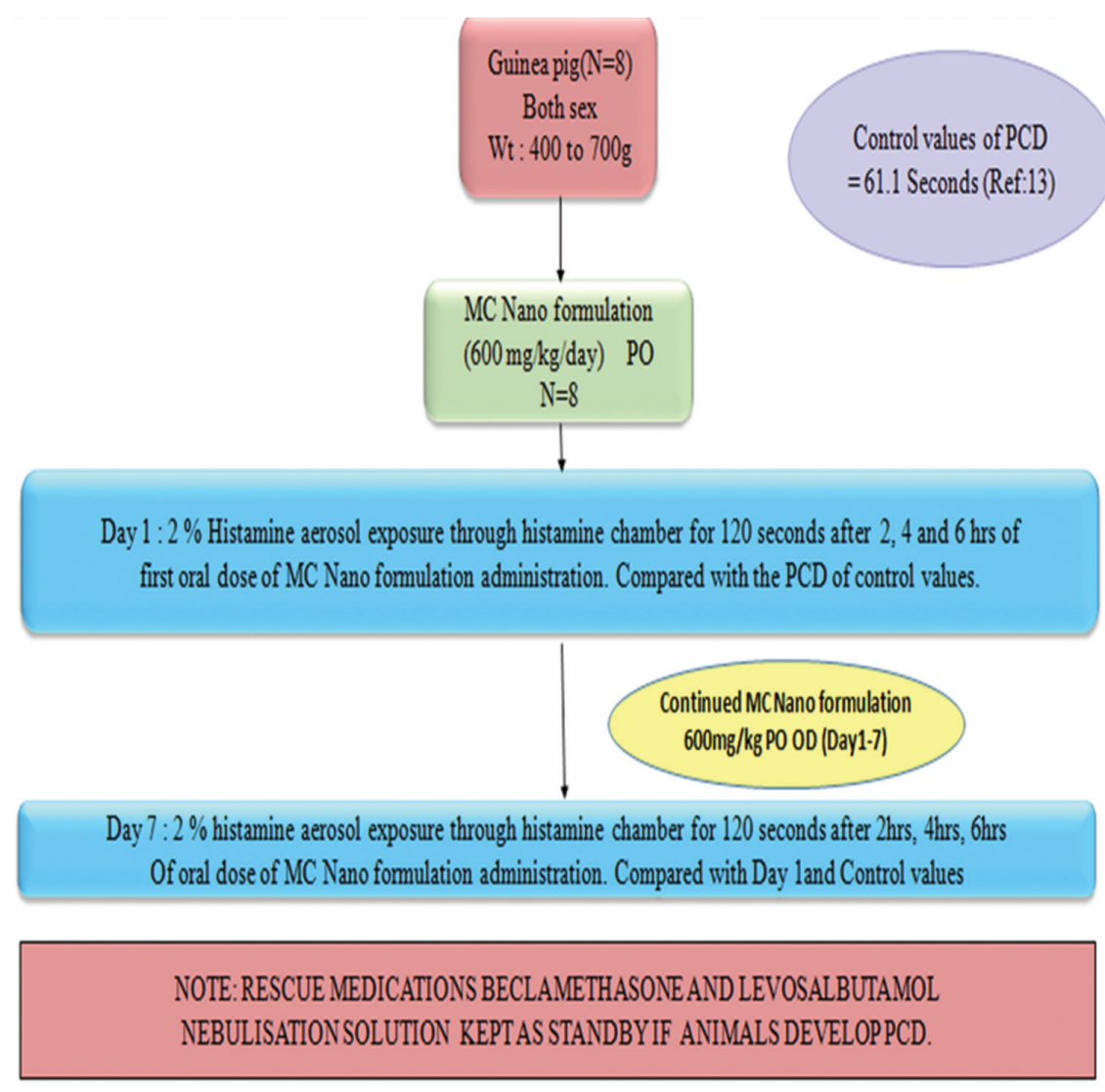

Fig. 1: Study method to assess the potency of Momordica charantia dry powder and nano dry powder in whole animal model

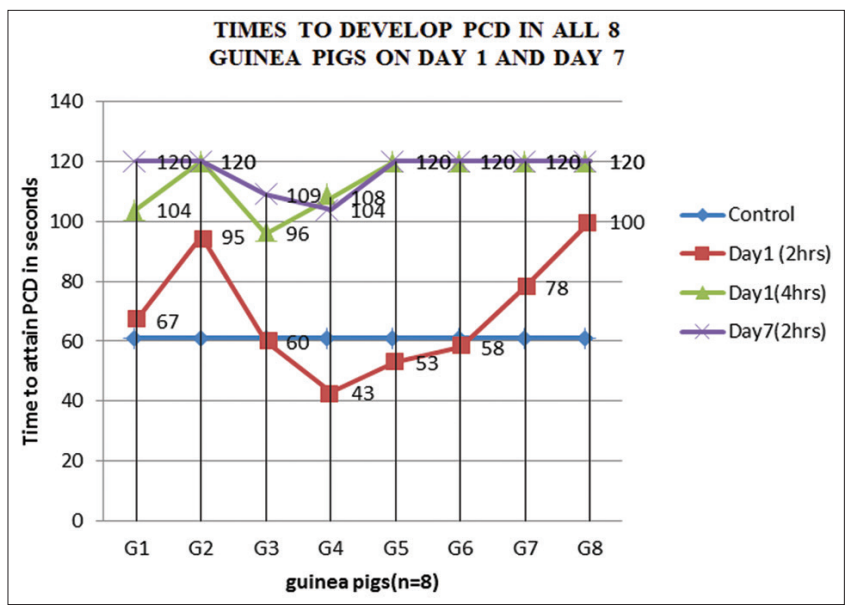

Fig. 2: Time to develop preconvulsive dyspnea on day 1 after $2 \mathrm{~h}$ and $4 \mathrm{~h}$ and day 7 after $2 \mathrm{~h}$ of Momordica charantia nanoformulation administration was terminated on day 1 . Tables 3 and 4 also illustrate cumulative doses of nanoformulation of MC given from day 1 to day 7 evidently showed that the effect was observed early. On day 7, 75\% of animals were completely protected from PCD after $2 \mathrm{~h}$ of the nanoformulation administration (Fig. 2).

Statistical significance is shown with ANOVA test for a collective comparison between day 1 values at $2 \mathrm{~h}$ and $4 \mathrm{~h}$ and day 7 values at 2 h. Post hoc ANOVA comparison was done with control values and three values, respectively. This demonstrated the statistical significance $(\mathrm{p}<0.01)^{*}$ of animal protection from developing PCD at $4^{\text {th }} \mathrm{h}$ value of day 1 and $2^{\text {nd }} \mathrm{h}$ value at day 7 (Table 3 ).

\section{CONCLUSION}

MC nanoformulation is found to be more efficient and potent in bringing pharmacological effect and protecting the animal from bronchospasm in comparison to $\mathrm{MC}$ dry powder and fresh juice. Nanoformulation is obtaining wide popularity in the pharmacotherapy for its better bioavailability, potency, and efficacy. MC being a natural product together with the optimization of the product into nanoparticles with 
PEG and soy phosphatidylcholine has proved to be a potent formulation than the crude dry powder. Hence, this study can become a future platform to compare MC nanoformulation as an adjuvant management in the standard care of treatment for bronchial asthma after effective clinical trials.

\section{ACKNOWLEDGMENT}

As authors, we would like to thank PSG Institutions - Management and the Dean, PSG IMS and R and Hospital who provided us the infrastructure to complete the study. We also express our heartfelt thanks to the Principal, PSG College of Pharmacy, Dr. V. Shankar, Professor and Head, Mr. Karthick Siram, Assistant professor, Department of Pharmaceutics, PSG College of Pharmacy, for their kind technical support which made this study successfully. Furthermore, we thank all the technicians, laboratory assistants of the Department of Pharmacology, PSG IMS and R, PSG Animal Facility, Coimbatore, for their countless help in performing this research.

\section{AUTHORS' CONTRIBUTIONS}

Bhuvaneswari et al., the corresponding author designed and supervised the study. Karthika P and Balachander R, the Principle investigator and coprinciple investigator, respectively, carried out the experimental work and drafted the manuscript. All the authors were involved in manuscript editing and finalization. All authors read and approved the final manuscript.

\section{CONFLICTS OF INTEREST}

All authors have no conflicts of interest to declare.

\section{FUNDING}

Self-funded.

\section{REFERENCES}

1. Grover JK, Yadav SP. Pharmacological actions and potential uses of Momordica charantia: A review. J Ethnopharmacol 2004;93:123-32.
2. Sathishsekar D, Subramanian S. Antioxidant properties of Momordica charantia (bitter gourd) seeds on streptozotocin induced diabetic rats. Asia Pac J Clin Nutr 2005;14:153-8.

3. Senanayake GV, Maruyama M, Shibuya K, Sakono M, Fukuda N, Morishita T, et al. The effects of bitter melon (Momordica charantia) on serum and liver triglyceride levels in rats. J Ethnopharmacol 2004;91:257-62

4. Cunnick JE, Sakamoto K, Chapes SK, Fortner GW, Takemoto DJ. Induction of tumor cytotoxic immune cells using a protein from the bitter melon (Momordica charantia). Cell Immunol 1990;126:278-89.

5. Srivastava AK, Mishra A, Gautam S, Pal S, Mishra A, Kumar AR, et al. Effect of Momordica charantia fruits on streptozotocin-induced diabetes mellitus and its associated complications. Int J Pharm Pharm Sci 2015;7:356-63.

6. Navya G, Shirisha Y, Girija P, Venkateshwarlu K, Sirisha K. Effect of Momordica charantia and Syzygium cumini extract on serum electrolytes in alloxan induced diabetic rats. Int J Pharm Pharm Sci 2018;11:24-7.

7. Frossard N, Freund V, Advenier C. Nerve growth factor and its receptors in asthma and inflammation. Eur J Pharmacol 2004;500:453-65.

8. Vllasaliu D, Fowler R, Stolnik S. PEGylated nanomedicines: Recent progress and remaining concerns. Expert Opin Drug Deliv 2014;11:139-54.

9. Singh U, Sagar VR. Effect of drying methods on nutritional composition of dehydrated bitter gourd (Momordica charantia). Indian agricultural research institute, New Delhi-12. Agric Sustain Dev 2013;1:83-86.

10. Tiruwa R. A review on nanoparticles-preparation and evaluation parameters. Indian J Pharm Biol Res 2016;4:27-8.

11. Pinzaru I, Coricovac D, Dehelean C, Moacă EA, Mioc M, Baderca F, et al. Stable PEG-coated silver nanoparticles a comprehensive toxicological profile. Food Chem Toxicol 2018;111:546-56.

12. Singh S, Agrawal SS. Anti-asthmatic and anti-inflammatory activity of Ocimum sanctum. Int J pharm 1991;29:306-10.

13. Sridevi G, Gopkumar P, Ashok S, Shastry C. Pharmacological basis for antianaphylactic, antihistaminic and mast cell stabilization activity of Ocimum sanctum. Internet J. Pharmacol 2009;7:22-5.

14. Bhuvaneswari K, Swarna RM, Amudhan A. Anti asthmatic effect of Momordica charantia and its comparison with montelukast an in vitro and in vivo model. Int J Basic Clin Pharmacol 2017;6:1810-5.

15. Ichinose M, Barnes PJ. Histamine H3-receptors modulate nonadrenergic noncholinergic neural bronchoconstriction in guinea-pig in vivo. Eur J Pharmacol 1989;174:49-55. 